\title{
The treatment of vesicoureteral reflux in children by endoscopic sub-mucosal intra-ureteral injection of dextranomer/hyaluronic acid: A case-series, multi-centre study
}

\author{
Osama Bawazir
}

MD, Consultant Paediatric Surgeon, Department of Surgery, Faculty of Medicine, Umm Al-qura University, Mecca, Kingdom of Saudi Arabia

\section{Type of article: Original}

\begin{abstract}
Background: Vesicoureteral reflux is a risk factor for progressive renal damage. In addition to long-term antibiotic prophylaxis and open surgical re-implantation, endoscopic sub-mucosal intra-ureteral injection of implant material is a therapeutic alternative that gained a world-wide preference.

Objective: The aim of this study was to determine the effectiveness and safety of the implant material, dextranomer/hyaluronic acid, in a cohort of Saudi children with vesicoureteral reflux.

Methods: In this case-series study, 61 patients with vesicoureteral reflux, who were 7 months to 10 years old (mean age 2.6 years), underwent sub-mucosal intra-ureteral injection of dextranomer/hyaluronic acid at our institutions in the period from October 2003 to October 2013. The operative protocol was the same in all institutions. Dextranomer/hyaluronic acid was injected submucosally within the intramural ureter (modified STING). Renal ultrasonography was performed to detect the presence of hydronephrosis. At 6 weeks' fluoroscopic voiding cystourethrograms were used to evaluate the success of the technique. Data were analysed by SPSS version 19 using Pearson Chi square, Fisher's Exact and Cramér's V test.

Results: Reflux was corrected in 44 patients out of $61(72.13 \%)$ and in $60(75.00 \%)$ out of 80 ureteric units. Statistically, there was no significant difference $(\mathrm{p}>0.05)$ in success rate of the technique according to gender, age group and unilateral vs. bilateral cases. The success rate was significantly $(\mathrm{p}=0.025)$ higher in the lower grades (IIII) $(87.50 \%)$ compared to grade IV $(73.53 \%)$ and grade V $(50.00 \%)$. No complications related to the technique were reported. The technique had failed in 17 patients $(27.87 \%)$ or 20 ureters $(25.00 \%)$. These cases underwent open surgery.

Conclusion: Sub-mucosal intra-ureteral implantation with dextranomer/hyaluronic acid by the modified STING technique is a simple, safe and effective outpatient procedure for vesicoureteral reflux.

Keywords: Vesicoureteral reflux; VUR; Dextranomer/hyaluronic acid; Dx\HA; Deflux; Modified STING
\end{abstract}

\section{Introduction}

In the paediatric and adolescent groups, vesicoureteral reflux (VUR) is a frequent urological anomaly with a prevalence of $1-3 \%$ in those with good health $(1,2)$. Urinary tract infection (UTI) is the most frequent presenting symptom, as about $31 \%$ of children presenting with UTI have VUR $(2,3)$. In addition, scarring of the kidney and its subsequent permanent renal damage can occur in $15 \%$ of patients $(1,3,4)$. During the past decades, the management of VUR has been noticeably modified with the aim to prevent renal damage. However, there is no consensus about the timing of using surgical and medical therapies (5). Long-term usage of antibiotic prophylaxis is one of the current options of treatment for these cases, but it still has the risk of renal damage, and patients' compliance to medication is another problem (6-9). Another option is surgical correction by either open or laparoscopic approach. Though these procedures have good success rates, they are not without complications (10). Since the introduction of the sub-ureteral injection of Teflon in 1984, endoscopic management of VUR has become a well-known alternative to the two previously mentioned options $(11,12)$. Hence, various implant materials like Teflon, silicon, bovine

\section{Corresponding author:}

Dr. Osama Abdullah Bawazir, Department of Surgery, Faculty of Medicine, Umm Al-qura University, Mecca, Kingdom of Saudi Arabia, Tel: +966503660669, Fax: +966125270000-4125, Email: obawazir@yahoo.com

Received: January 10, 2017, Accepted: March 28, 2017, Published: April 2017

iThenticate screening: March 27, 2017, English editing: April 06, 2017, Quality control: April 12, 2017

(C) 2017 The Authors. This is an open access article under the terms of the Creative Commons Attribution-NonCommercialNoDerivs License, which permits use and distribution in any medium, provided the original work is properly cited, the use is non-commercial and no modifications or adaptations are made. 
collagen and many others have been used for this purpose (13). Currently, the most widely-used agent is dextranomer/hyaluronic acid (Dx\HA) copolymer (Deflux). It is dextranomer microspheres in hyaluronic acid solution. Dx\HA is biodegradable, non-carcinogenic and non-immunogenic (14). The objective and rationale behind this study was to determine the effectiveness of endoscopic sub-ureteral dextranomer/ hyaluronic acid copolymer, via the modified STING procedure for management of patients with VUR, in term of success rate.

\section{Material and Methods}

\subsection{Study design and participants}

This study was a descriptive case series study. It adopted the standards of GCP and in conformity with the latest revision of the Declaration of Helsinki. In addition, it was approved by institutions review boards and local ethics committees. A total of 61 children, boys or girls, 7 months to 10 years old (mean age 2.6 years) with primary VUR from King Faisal specialist hospital and Bakhsh Hospital in Jeddah-KSA, were enrolled in the period from October 2003 to October 2013.

\subsection{Selection criteria}

The standard indications for the intervention were progressive renal damage, recurrent urinary tract infection, noncompliance with medications and preference of the parents. Exclusion criteria were children with ectopic ureter who were offered another therapeutic option and children with Von Willebrand disease.

\subsection{Data collection}

The purpose of this study was clearly explained in Arabic language to parents of all subjects attending the institutions before their enrolment to the study, and an informed consent form was signed by parents of all of those enrolled. All children who enrolled to the study were diagnosed as having VUR with the aid of voiding cystourethrograms (VCUG). The operative protocol of the technique was the same for all surgery teams in all institutions, with the child under general anaesthesia, placed in the lithotomy position. All patients received prophylactic parenteral antibiotic before the technique. A paediatric cystoscope was used, according to gender and age, with the bladder filled to about three quarters. Hydrodistention was used for all patients to open the ureteral orifices (15). Sub-mucosal injection of 0.2-1.5 ml of Dx\HA per ureter within the intramural ureter (modified STING) was done in all cases; according to age and size of the ureteral orifice; until complete coaptation of the ureteral orifice. Prophylactic antibiotics were maintained until resolution of reflux as documented on the postoperative evaluation. Renal and bladder ultrasonography was performed the next day before discharge to detect the presence of hydronephrosis. At 6 weeks, fluoroscopic VCUG was performed for all patients to evaluate the status of presence or absence of VUR.

\subsection{Statistical analysis}

The primary outcome of this study was the reflux status (correction or failure). Secondary outcomes included occurrence of adverse events as gross hematuria, de novo contra-lateral VUR, flank pain, hydronephrosis, increase serum creatinine, or UTI. The outcomes were analyzed by overall sample. Subgroup analyses were carried out by age group, gender, side, grade and singe-duplex collecting systems. All statistical tests were done using a significance level of $95 \%$. A value of $\mathrm{p}<0.05$ was considered statistically significant. IBM $\odot$ SPSS $\odot$ Statistics version 19 (IBMC Corp., Armonk, NY, USA) was used for the statistical analysis. Data were presented as mean and range for continuous variables and as frequency \& percent for categorical variables. Comparisons were done using Pearson Chi square, Fisher's Exact and Cramér's V test.

\section{Results}

\subsection{Baseline characteristics}

In this study, 61 subjects (46 girls and 15 boys) were enrolled and followed up, with average age of 2.6 years and a range from 7 months to 10 years. Forty-two children had a unilateral VUR and 19 bilateral that made a total of 80 refluxing ureters to be treated in all 61 children. Thirty-two ureters (out of the 80 ureters) had lower grades I-III VUR, 34 grade IV and only 14 ureters had grade V VUR. Most of the ureters (76 ureters) had single ureteric units and only 4 were duplicate units. The baseline characteristics of subjects are shown in Table 1.

\subsection{Success rate of the technique}

Reflux was corrected in 44 patients out of $61(72.13 \%)$ and in $60(75.00 \%)$ out of 80 ureteric units. Statistically, there was no significant difference $(\mathrm{p}=0.587)$ in success rate of the procedure between the two genders, as shown in Table 1. The success rate of the procedure did not differ in cases with unilateral vs. bilateral VUR ( $\mathrm{p}=0.293)$, as 
shown in Table 1. The success rate of the procedure was more in lower grades (I-III) of VUR $(87.50 \%)$ compared to grade IV $(73.53 \%)$ and grade V $(50.00 \%)$. The difference is statistically significant, $(\mathrm{p}=0.025)$. Statistically, there was no significant $(\mathrm{p}=0.515)$ difference in success rate of the procedure according to age group, as shown in Table 1. Moreover, the success rate was not different $(\mathrm{p}=0.259)$ between single ureteric unit vs. duplicate ureteric units, as shown in Table 1. Repeated injection was required in 5 patients with VUR grades I-III which resulted in complete resolution in all of them. In addition, four patients had intra-operative VCUG. Then, they had another VCUG 6 weeks later. One of these patients showed the presence of the reflux at the later VCUG. The modified STING technique had failed to correct VUR in 17 patients $(27.87 \%)$ or 20 ureters $(25.00 \%)$. These cases underwent ureteral re-implantation operation. There have been no complications related to Dx\HA injection.

Table 1: Baseline characteristics and success rate of the modified STING technique

\begin{tabular}{|l|l|l|l|l|}
\hline Variables & Number of children & Success rate, n (\%) & $\mathrm{p}$-value \\
\hline \multirow{3}{*}{ Gender } & Female & 46 & $34(73.91)$ & 0.587 \\
\cline { 2 - 5 } & Male & 15 & $10(66.67)$ & \\
\hline \multirow{3}{*}{ Side } & Unilateral & 42 & $32(76.19)$ & 0.293 \\
\cline { 2 - 5 } & Bilateral & 19 & $12(63.16)$ & \\
\cline { 2 - 5 } & Total & 61 & $44(72.13)$ & \\
\hline \multirow{3}{*}{ Age (year) } & & Number of ureteric units & Success rate, n (\%) & $\mathrm{p}$-value \\
\cline { 2 - 5 } & $\leq 4$ & 35 & $25(71.42)$ & 0.515 \\
\hline \multirow{3}{*}{ Grade } & I-III & 45 & $35(77.78)$ & \\
\cline { 2 - 5 } & IV & 34 & $28(87.50)$ & 0.025 \\
\cline { 2 - 5 } & V & 14 & $25(73.53)$ & \\
\hline \multirow{3}{*}{ Ureteric unit } & Single & 76 & $7(50.00)$ & \\
\cline { 2 - 6 } & Duplicate & 4 & $58(76.32)$ & 0.259 \\
\cline { 2 - 5 } & Total & 80 & $60(75.00)$ & \\
\hline
\end{tabular}

\section{Discussion}

Since the introduction of bulking agents for endoscopic correction of VUR, the spectrum of management of such urological anomaly has been broadened and the technique has become the first-line treatment adopted by most institutions all over the world (14). Several materials have been tried and evaluated as bulking agents during the last three decades. The most important disadvantages of these agents were immunogenicity and particle migration (1619). However, after the introduction of Dx\HA by Stenberg and Lackgren (19) in 1995, with its bigger size, the likelihood of particle migration seen in other agents has been decreased significantly. Moreover, Dx $\backslash \mathrm{HA}$ is nonimmunogenic, non-carcinogenic and biodegradable (20). The main objective of this current study was to study the effectiveness of endoscopic sub-ureteral Dx\HA for management of children with VUR in Saudi Arabia in terms of success rate. Our study showed that VUR was corrected in $72.13 \%$ of patients and in $75.00 \%$ of ureteric units overall, with a higher success rate $(87.50 \%)$ in the low-grades VUR. The success rate of the procedure was not different according to gender, age group, unilateral vs. bilateral or single ureteric unit vs. duplicate ureteric units. The success rate of the procedure was more in lower grades (I-III) of VUR compared to grade IV and grade V. Repeated injection was required only in 5 patients with success in all of them. There have been no complications

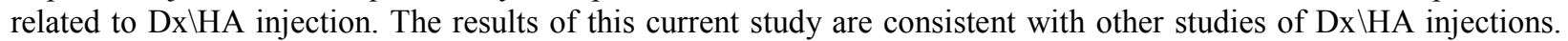
The overall success rate in our study is within that range (68-92\%) of other studies with the higher success rates in the lower VUR grades $(15,21-27)$. The modified STING technique with the hydrodistention implantation, increased the success rate to $92 \%$ compared to the conventional STING procedure $(79 \%)$ (15). The high efficacy of this endoscopic treatment for VUR, with its low invasiveness, led to many investigators to suggest it as a first-line treatment for these cases especially before surgery $(15,25-30)$. Furthermore, the higher success rate in the lower grades VUR made it an important alternative to long-term antibiotic prophylaxis (31). Moreover, similar to results of other published studies in the literature, no adverse effect has been noticed in our series (22-25). One advantage of this current study is being a prospective multi-centre study using Dx\HA with favourable success rate and with no adverse effects recorded. On the other hand, one limitation of the study is the lack of recurrence data. This is because no follow up data have been collected after the 6 week post-operative care. Another limitation of the study is being single-arm and non-comparative; hence, we recommend doing further RCTs to compare the Dx $\backslash \mathrm{HA}$ to other agents or to surgical re-implantation in our population. However, Dx\HA is the most studied bulking agent among others. 


\section{Conclusions}

Endoscopic sub-mucosal intra-ureteral implantation with Dx\HA with the modified STING technique is simple, safe and effective outpatient procedure for the management of VUR. Thus, we recommend it as a first-line treatment for grades up to grade IV VUR.

\section{Acknowledgments:}

The author is grateful to King Faisal Specialist Hospital KFSHRC-Jeddah and Bakhsh Hospital -Jeddah where these patients were managed. The author thanks the Department of Surgery and Radiology in both hospitals for the technical assistance.

\section{Conflict of Interest:}

Author has no conflict of interests, the work was not supported or funded by any drug company and the author declare that he has no competing interests.

\section{References:}

1) Jacobson SH, Hansson S, Jakobsson B. Vesicoureteric reflux: Occurrence and long term risks. Acta Paediatr Suppl. 1999; 88(431): 22-30. doi: 10.1111/j.1651-2227.1999.tb01315.x. PMID: 10588268.

2) Sargent MA. What is the normal prevalence of vesicoureteral reflux? Pediatr Radiol. 2000; 30(9): 587-93. doi: 10.1007/s002470000263. PMID: 11009294.

3) Bundy DG. Vesicoureteral reflux. Pediatr Rev. 2007; 28(2): e6-8. doi: 10.1542/pir.28-2-e6. PMID: 17272519 .

4) Montini G, Toffolo A, Zucchetta P, Dall'Amico R, Gobber D, Calderan A, et al. Antibiotic treatment for pyelonephritis in children: multicentre randomised controlled noninferiority trial. BMJ. 2007; 335(7616): 386. doi: 10.1136/bmj.39244.692442.55. PMID: 17611232, PMCID: PMC1955287.

5) Elder JS. Guidelines for consideration for surgical repair of vesicoureteral reflux. Curr Opin Urol. 2000; 10(6): 579-85. doi: 10.1097/00042307-200011000-00008. PMID: 11148729.

6) Mattoo TK. Vesicoureteral reflux and reflux nephropathy. Adv Chronic Kidney Dis. 2011; 18(5): 348-54. doi: 10.1053/j.ackd.2011.07.006. PMID: 21896376, PMCID: PMC3169795.

7) American Urological Association: Report on the management of primary vesicoureteral reflux in children. Baltimore: American Urological Association, 1997.

8) Smellie JM, Jodal U, Lax H, Möbius TT, Hirche H, Olbing H. Outcome at 10 years of severe vesicoureteric reflux managed medically: Report of the International Reflux Study in Children. J Paediatr. 2001; 139(5): 656-63. doi: 10.1067/mpd.2001.117583. PMID: 11713442.

9) Wan J, Greenfield SP, Talley M, Ng M. An analysis of social and economic factors associated with follow up of patients with vesicoureteral reflux. J Urol. 1996; 156(2 Pt 2): 668-72. doi: 10.1016/S00225347(01)65780-X. PMID: 8683756.

10) Mouriquand PDE. Surgical treatment of vesicoureteric reflux. In: Rob \& Smith's Operative Surgery: Paediatric Surgery. Edited by Spitz L and Coran AG. London: Butterworth; 1995: 638642.

11) O’Donnell B, Puri P. Treatment of vesicoureteric reflux by endoscopic injection of Teflon. Br Med J. 1984; 289: 79. doi: $10.1136 / \mathrm{bmj} .288 .6410 .79$.

12) Puri P, O'Donnell B. Correction of experimentally produced vesicoureteric reflux in the piglet by intravesical injection of Teflon. $\mathrm{Br}$ Med $\mathrm{J}$ (Clin Res Ed). 1984; 289(6436): 5-7. doi: 10.1136/bmj.289.6436.5. PMID: 6428663, PMCID: PMC1442059.

13) Schulman CC. Uroplastique new microimplants for the endoscopic correction of reflux. Abstract of EAU congress. 1992; 375: V59.

14) Chandrasekharam VV. Endoscopic treatment of vesicoureteric reflux with dextranomer/hyaluronic acid copolymer (Deflux): Single surgeon experience with 48 ureters. Indian J Urol. 2013; 29(3): 173-6. doi: 10.4103/0970-1591.117269. PMID: 24082435, PMCID: PMC3783694.

15) Kirsch AJ, Perez-Brayfield M, Smith EA, Scherz HC. The modified sting procedure to correct vesicoureteral reflux: improved results with submucosal implantation within the intramural ureter. J Urol. 2004; 171(6 Pt 1): 2413-6. doi: 10.1097/01.ju.0000127754.79866.7f. PMID: 15126864.

16) Aaronson IA, Rames RA, Greene WB, Walsh LG, Hasal UA, Garen PD. Endoscopic treatment of reflux migration of Teflon to the lungs and brain. Eur Urol. 1993; 23(3): 394-9. PMID: 8508896.

17) Malizia AA Jr, Reiman HM, Myers RP, Sande JR, Barham SS, Benson RC Jr, et al. Migration and granulomatous reaction after periurethral injection of polytef (Teflon). JAMA. 1984; 251(24): 3277-81. doi: 10.1001/jama.1984.03340480059030. PMID: 6374180. 
18) Allen O. Response to subdermal implantation of textured microimplants in humans. Aesthetic Plast Surg. 1992; 16(3): 227-30. doi: 10.1007/BF00190068. PMID: 1626459.

19) Stenberg A, Lackgren G. A new bio-implant for the endoscopic treatment of vesicoureteral reflux: Experimental and short-term clinical results. J Urol. 1995; 154(2 Pt 2): 800-3. PMID: 7541869.

20) Stenberg AM, Sundin A, Larsson BS, Stenberg A. Lack of distant migration after injection of a 125 -iodine labelled dextranomer/hyaluronic acid copolymer: Preliminary results. J Urol. 1997; 158(5): 1937-41. doi: 10.1016/S0022-5347(01)64185-5.

21) Oswald J, Riccabona M, Lusuardi L, Bartsch G, Radmayr C. Prospective comparison and 1-year follow-up of a single endoscopic subureteral polydimethylsiloxane versus dextranomer/hyaluronic acid copolymer injection for treatment of vesicoureteral reflux in children. Urology. 2002; 60(5): 894-7. doi: 10.1016/S0090-4295(02)01903-9. PMID: 12429323.

22) Lavelle MT, Conlin MJ, Skoog SJ. Subureteral injection of Deflux for correction of reflux: Analysis of factors predicting success. Urology. 2005; 65(3): 564-7. doi: 10.1016/j.urology.2004.09.068. PMID: 15780377.

23) Puri P, Pirker M, Mohanan N, Dawrant M, Dass L, Colhoun E. Subureteral dextranomer/hyaluronic acid injection as first line treatment in the management of high grade vesicoureteral reflux. J Urol. 2006; 176(4 Pt 2): 1856-9. doi: 10.1016/j.juro.2006.03.124. PMID: 16945672.

24) Moltierno JA, Scherz HC, Kirsch AJ. Endoscopic treatment of vesicoureteric reflux using Dextranomer Hyaluronic acid copolymer. J Pediatrc Urol. 2008; 4(3): 221-8. doi: 10.1016/j.jpurol.2007.11.015. PMID: 18631931.

25) Puri P, Chertin B, Velayudham M, Dass L, Colhoun E. Treatment of vesicoureteral reflux by endoscopic injection of dextranomer/hyaluronic acid copolymer: Preliminary results. J Urol. 2003; 170(4 Pt 2): 1541-4. doi: 10.1097/01.ju.0000083924.44779.80. PMID: 14501655.

26) Perez-Brayfield M, Kirsch AJ, Hensle TW, Koyle MA, Furness P, Scherz HC. Endoscopic treatment with dextranomer/hyaluronic acid for complex cases of vesicoureteral reflux. J Urol. 2004; 172(4 Pt 2): 1614-6. doi: 10.1097/01.ju.0000139013.00908.1c. PMID: 15371773.

27) Chertin B, Colhoun E, Velayudham M, Puri P. Endoscopic treatment of vesicoureteral reflux: 11 to 17 years of followup. J Urol. 2002; 167(3): 1443-5. doi: 10.1016/S0022-5347(05)65340-2. PMID: 11832767.

28) Stenberg A, Hensle TW, Lackgren G. Vesicoureteral reflux: a new treatment algorithm. Curr Urol Rep. 2002; 3(2): 107-14. doi: 10.1007/s11934-002-0020-9. PMID: 12084201.

29) Elmore JM, Kirsch AJ, Lyles RH, Perez-Brayfield MR, Scherz HC. New contralateral vesicoureteral reflux following dextranomer/hyaluronic acid implantation: incidence and identification of a high risk group. J Urol. 2006; 175(3): 1097-1101. doi: 10.1016/S0022-5347(05)00405-2. PMID: 16469630.

30) Chertin B, Puri P. Endoscopic management of vesicoureteral reflux: does it stand the test of time? Eur Urol. 2002; 42(6): 598-606. doi: 10.1016/S0302-2838(02)00447-5. PMID: 12477657.

31) Heidenreich A, Ozgur E, Becker T, Haupt G. Surgical management of vesicoureteral reflux in pediatric patients. World J Urol. 2004; 22(2): 96-106. doi: 10.1007/s00345-004-0408-x. PMID: 15221260. 